\title{
Advanced nanofibrous textile-based dressing material for treating chronic wounds
}

\author{
ISABEL HERRMANN ${ }^{1,2}$, EKO SUPRIYANTO ${ }^{1}$, SARAVANA KUMAR JAGANATHAN ${ }^{3,4,5, *}$ and \\ A MANIKANDAN ${ }^{6}$ \\ ${ }^{1}$ Faculty of Biosciences and Medical Engineering, Universiti Teknologi Malaysia, Skudai 81300, Malaysia \\ ${ }^{2}$ Ilmenau Institute of Biomedical Engineering and Computer Science, Technical University of Ilmenau, 98693 Ilmenau, \\ Germany \\ ${ }^{3}$ Department for Management of Science and Technology Development, Ton Duc Thang University, Ho Chi Minh City, \\ Vietnam \\ ${ }^{4}$ Faculty of Applied Sciences, Ton Duc Thang University, Ho Chi Minh City, Vietnam \\ ${ }^{5}$ IJNUTM Cardiovascular Engineering Centre, Department of Clinical Sciences, Faculty of Biosciences and Medical \\ Engineering, Universiti Teknologi Malaysia, Skudai 81300, Malaysia \\ ${ }^{6}$ Department of Chemistry, Bharath Institute of Higher Education and Research, Bharath University, Chennai 600073, \\ India \\ *Author for correspondence (saravana@tdt.edu.vn)
}

MS received 17 February 2017; accepted 3 May 2017; published online 2 February 2018

\begin{abstract}
In the present work, an electrospun nanofibrous textile composed of polyurethane (PU), sodium bicarbonate $\left(\mathrm{NaHCO}_{3}\right)$ and pantothenic acid (PA) is developed for treating chronic wounds. Wounds are a common health problem and in particular, the chronic wounds such as vascular ulcers, diabetic ulcers and pressure ulcers cause a large number of morbidity and mortality. The main problems of the chronic wounds are prolonged inflammation phase and presence of acidic environment. These events deactivate the operation of growth factors and also the progression of natural healing mechanism. Hence, various types of advanced textile-based dressings are developed to address the clinical complications associated with chronic wound management. The prepared electrospun scaffolds were characterized to study their physicochemical and haemocompatible properties. The scanning electron microscopy micrographs depicted continuous, smooth-interconnected nanofibrous morphology of PU- $\mathrm{NaHCO}_{3}-\mathrm{PA}$ scaffolds. The Fourier transform infrared spectroscopy spectra indicated the addition of $\mathrm{NaHCO}_{3}$ and $\mathrm{PA}$-based hydrophilic chemical groups, which significantly enhanced the wettability of the composites. Further, the PU-NaHCO $3-\mathrm{PA}$ composite membrane inferred to have a highly porous structure with the mean porosity of $79.4 \pm 4.8 \%$, which may provide a conducive environment for adherence and proliferation of skin cells. The composite scaffold also offers a highly haemocompatible surface by delaying coagulation of blood through contact activation pathways and by limiting red blood cells damage. Therefore, the excellent physicochemical properties, blood compatibility and the delivery of PA are anticipated to speed up the impaired healing process of chronic wounds.
\end{abstract}

Keywords. Advanced textiles; chronic wound healing; electrospinning; sodium bicarbonate; pantothenic acid.

\section{Introduction}

Medical textiles have various applications in the biomedical field, and over the years, techniques and methods of developing materials have improved tremendously. As a result, new innovative and advanced textiles with excellent properties are introduced in the market each year. The crucial qualities, such as non-toxic, haemostatic, non-allergic, bacteriostatic and biocompatibility have expanded the popularity of advanced textiles especially in wound healing field [1,2]. A few decades ago, the main function of the dressing material was to cover the wound site and to get hold of the bleeding. Later, drugs were added and its physicochemical properties were also tailored to enable the absorption of exudates along with the ability to support nutrient exchange, better breathability and shielding microbial growth $[3,4]$. Because of the rapid developments in the nanotechnology field, the current advanced medical textiles not only mimic tissue structure, but also release the payload based on the microenvironment cues or demand at the wound site. Hence, a huge amount of investments are reported to develop the smart advanced materials and it is anticipated to boost the market for medical textiles in coming years $[1,4]$.

Wounds are a common health problem, though there are different types, it is mostly classified into acute and chronic wounds. The acute wounds progress well through overlapping phases-haemostasis, inflammation, proliferation and remodelling - of the natural healing process. However, chronic wounds such as vascular ulcers (venous and arterial ulcers), diabetic ulcers and pressure ulcers stop in the inflammation phase for a long period $[5,6]$. Hence, the growth factors get degrade and the excessive protease 
levels destruct extracellular matrix (ECM), which end up recruiting more immune cells. They eventually produce a higher amount of reactive oxygen species (ROS) and cause further cell damage. These events not only amplify the duration of inflammation phase, but also cause persistent infections and the formation of biofilms (drug-resistant). Consecutively, the recruited fibroblasts and endothelial cells stop responding to the reparative stimuli and halt the progression of healing cycle [6]. The chronic ulcers typically take years to complete remission, but in $60-70 \%$ of cases, recurrence is reported and leads to loss of function and morbidity. Each year, the chronic ulcers are reported to affect an estimated 2.4-4.5 million people in the United States and nearly half of them are hospitalized $[7,8]$. To control the loss of life, nowadays, the traditional dressings such as cotton, wool, natural or synthetic bandages and gauzes are largely replaced by novel advanced dressings and therapies.

The dressing used to treat chronic wounds should be able to mimic the native tissue structure and also release the payload according to the local cues to achieve complete remission. Though, advanced formulations such as micelles, hydrogels, dendrimers, microcapsules, etc. are used to deliver drugs in various applications, none offer mechanical support to the regenerating tissue. To combat above complication, the textile-based manufacturing technique such as electrospinning can be utilized. The electrospun nanofibre mats, unlike traditional bandages and aforementioned formulations, possess several features of an ideal dressing. The properties like high surface-to-volume ratio, interconnected porosity, compatible morphology and gas permeation promote cell attachment, regeneration and haemostasis [5,9]. Further, the electrospun mats can be synthesized using a variety of polymers with the easy incorporation of biomolecules. Thus, it can be tailored to offer personalized therapy and can be applied to virtually any type of wound surface. Therefore, in this work, a novel polyurethane (PU)-based composite scaffold was developed to reduce the complications in chronic wound management. PU is one of the most common synthetic polymers traditionally used as a dressing material because of their high biocompatibility, good permeability to oxygen and carbon dioxide, excellent mechanical strength and appropriate flexibility $[10,11]$.

The component pantothenic acid (PA) popularly called as vitamin $\mathrm{B}_{5}\left(\mathrm{VB}_{5}\right)$ is blended to accelerate the healing process. PA is commonly used in various cosmetic products as a moisturizer, but previous studies have proved its ability to reduce inflammation and assist the cells in surviving in highoxidative stress. In addition, it also reported to promote the migration and proliferation of fibroblasts and inferred to play a vital role in controlling the remodelling phase [12-14]. Along with PA, sodium bicarbonate $\left(\mathrm{NaHCO}_{3}\right)$ is also added to control its release according to the wound $\mathrm{pH}$ and to enhance the antimicrobial activity of the composite scaffold. Basically, the chronic wounds are depicted to have acidic $\mathrm{pH}$ which affects the action of growth factors and increase the inflammation reaction $[5,9]$. Hence, various types of $\mathrm{pH}$-responsive biodegradable polymers are manufactured by introducing acid-liable segments such as ortho-ester groups, acetal groups, etc. However, the complicated synthesis process and loss of mechanical function due to sudden breakage of chemical bonds limit its usage. It can be surpassed by using $\mathrm{NaHCO}_{3}$ because of its high reactivity. In an acidic environment, the $\mathrm{NaHCO}_{3}$ readily react with the protons $\left(\mathrm{H}^{+}\right)$and release $\mathrm{CO}_{2}$, which in turn accelerate the release of the payload by causing sudden burst. But, when the $\mathrm{pH}$ drops below 7.4 (normal range for skin) or became basic, the drug is reported to release in a steady manner $[15,16]$. By employing this strategy, the efficacy of natural wound healing process can be enhanced by controlling the inflammation. Meanwhile, the delivery of PA may increase the accumulation and proliferation of fibroblast at the wound site.

\section{Materials and methods}

\subsection{Materials}

The medical grade PU (Tecoflex EG 80A) was procured from Lubrizol Advanced Materials, Inc. (Thermedics Polymer Products, USA). And the materials, such as pantothenic acid $\mathrm{B}_{5}$ was received from Jarrow Formulas (Los Angeles) and $\mathrm{NaHCO}_{3}$ was purchased from HOLSTE (Germany). The solvents N,N-dimethylformamide (DMF) and chloroform $\left(\mathrm{CHCl}_{3}\right)$ of analytical grade were supplied by Merck Millipore, Germany. The phosphate buffered saline (PBS) of biotech grade was procured from Biobasic (Canada) and the natrium chloride, physiological saline $(0.9 \mathrm{wt} / \mathrm{vol})$ was supplied by Sigma-Aldrich, Malaysia. Further, the kits required to measure APTT and PT were purchased from Diagnostic Enterprises (India).

\subsection{Preparation of $\mathrm{PU}$ and $\mathrm{PU}-\mathrm{NaHCO}_{3}-\mathrm{PA}$ composite (just use the cellulose)}

The PU beads were dissolved in DMF overnight by continuous stirring to make a clear solution of $4 \%$ concentration (w/v). Then, the $\mathrm{PU}-\mathrm{NaHCO}_{3}-\mathrm{PA}$ composite was prepared by selecting suitable solvents to dissolve $\mathrm{PA}$ and $\mathrm{NaHCO}_{3}$ through different paths. Of the three different solvents used (DMF, $\mathrm{CHCl}_{3}$ and distilled water), PA was completely dissolved in DMF and formed an emulsion in $\mathrm{CHCl}_{3}$, while the $\mathrm{NaHCO}_{3}$ was soluble only in distilled water. To prepare the composite, the PA and $\mathrm{NaHCO}_{3}$ solutions were added with $\mathrm{PU}$ in different ratios and concentrations as summarized in table 1 . Initially, the sample $\mathrm{S} 1$ was prepared by adding PU (4\%), $\mathrm{NaHCO}_{3}(2 \%)$ and PA (2\%) in the ratio 8:1:1, however, the final solution was clogged and became unsuitable for electrospinning. In the trial $\mathrm{S} 2$, the proposed materials were added in same concentration and ratio alike $\mathrm{S} 1$, but $\mathrm{CHCl}_{3}$ was used to dissolve PA instead of DMF. Nevertheless, the end result was same, i.e., the solution clogged and phase separated. The clogging of the prepared composite can be attributed to the 
Table 1. Details of different trails carried out and its inference.

\begin{tabular}{|c|c|c|c|c|c|}
\hline Trial/sample name & Materials added & Solvents used & Concentration (w/v) & Mixing ratio & Inference \\
\hline S1 & $\mathrm{PU}, \mathrm{NaHCO}_{3}, \mathrm{PA}$ & $\begin{array}{l}\text { DMF, distilled } \\
\text { water, DMF }\end{array}$ & $4,2,2$ & $8: 1: 1$ & Clogged solution \\
\hline $\mathrm{S} 2$ & $\mathrm{PU}, \mathrm{NaHCO}_{3}, \mathrm{PA}$ & $\begin{array}{l}\text { DMF, distilled } \\
\text { water, } \mathrm{CHCl}_{3}\end{array}$ & $4,2,2$ & $8: 1: 1$ & Clogged solution \\
\hline S3 & $\mathrm{PU}, \mathrm{NaHCO}_{3}, \mathrm{PA}$ & $\begin{array}{l}\text { DMF, distilled } \\
\text { water, DMF }\end{array}$ & $4,1,3$ & $8: 2(1: 2)$ & $\begin{array}{l}\text { Stable solution (low } \\
\text { viscosity) }\end{array}$ \\
\hline S4 & $\mathrm{PU}, \mathrm{NaHCO}_{3}, \mathrm{PA}$ & $\begin{array}{l}\text { DMF, distilled } \\
\text { water, DMF }\end{array}$ & $4,1,2$ & $8: 2(1: 2)$ & $\begin{array}{l}\text { Stable solution } \\
\text { (medium } \\
\text { viscosity) }\end{array}$ \\
\hline S5 & $\mathrm{PU}, \mathrm{NaHCO}_{3}, \mathrm{PA}$ & $\begin{array}{l}\text { DMF, distilled } \\
\text { water, DMF }\end{array}$ & $4,1,2$ & $9: 1(1: 2)$ & $\begin{array}{l}\text { Stable solution } \\
\text { (viscous) }\end{array}$ \\
\hline
\end{tabular}

Table 2. Details of parameters at which the composite scaffolds were electrospun.

\begin{tabular}{|c|c|c|c|}
\hline Sample name & Applied voltage $(\mathrm{kV})$ & Flow rate $\left(\mathrm{ml} \mathrm{h}^{-1}\right)$ & Collector distance $(\mathrm{cm})$ \\
\hline $\mathrm{PU}-\mathrm{NaHCO}_{3}-\mathrm{PA} 1$ & 19.7 & $0.3-0.6$ & 15 \\
\hline $\mathrm{PU}-\mathrm{NaHCO}_{3}-\mathrm{PA} 2$ & 27 & 0.3 & 15 \\
\hline $\mathrm{PU}-\mathrm{NaHCO}_{3}-\mathrm{PA} 3$ & 17.9 & 0.3 & 15 \\
\hline $\mathrm{PU}-\mathrm{NaHCO}_{3}-\mathrm{PA} 4$ & 21.6 & 0.4 & 15 \\
\hline
\end{tabular}

usage of distilled water to dissolve $\mathrm{NaHCO}_{3}$, since water is a commonly used chemical blowing agent to solidify PU as reported previously [17]. This effect was avoided by reducing the concentration and mixing ratio of the $\mathrm{NaHCO}_{3}$ solution. Finally, three different stable and homogenous solutions ( 33 , $\mathrm{S} 4$ and S5) of PU-NaHCO $3-\mathrm{PA}$ composite was obtained and subjected to electrospinning (table 1).

\subsection{Electrospinning of $\mathrm{PU}$ and $\mathrm{PU}-\mathrm{NaHCO}_{3}-\mathrm{PA}$ composite}

The pristine PU (4\%) was loaded into a $10 \mathrm{ml}$ syringe attached to an $18-\mathrm{G}$ stainless steel needle and fitted to the syringe pump (SP20, NFiber). The voltage required for electrospinning was obtained from NFiber high-voltage power supply and the fibres were collected on a static drum collector covered with aluminium foil. The PU solution was electrospun at the flow rate of $0.700 \mathrm{ml} \mathrm{h}^{-1}$ with the applied voltage of $16 \mathrm{kV}$ and the collector was placed at a distance of $15 \mathrm{~cm}$. The addition of $\mathrm{PA}$ and $\mathrm{NaHCO}_{3}$ drastically altered the solution properties such as viscosity, etc., hence the voltage and the flow rate are to be changed to electrospun the $\mathrm{PU}-\mathrm{NaHCO}_{3}-\mathrm{PA}$ composite solutions as mentioned in table 2. The electrospun composite membranes were named as $\mathrm{PU}-\mathrm{NaHCO}_{3}-\mathrm{PA} 1, \mathrm{PU}-\mathrm{NaHCO}_{3}-\mathrm{PA} 2$, $\mathrm{PU}-\mathrm{NaHCO}_{3}-\mathrm{PA} 3$ and $\mathrm{PU}-\mathrm{NaHCO}_{3}-\mathrm{PA} 4$, respectively. The fabricated PU and composite membranes were dried at room temperature for $24 \mathrm{~h}$ before subjecting to characterization studies.

\subsection{Physicochemical characterization studies}

2.4a SEM: The morphology of the electrospun membranes was examined using scanning electron microscopy (SEM) (TM3000, Hitachi Ltd., Malaysia). Initially, the samples were coated with gold by a sputter coater (Polaron Division SEM coating system, Bio-Rad Laboratories, Singapore) for 2 min and imaged at $7000 \times$. The diameter size distribution in the fabricated membranes was determined using ImageJ (National Institutes of Health, Bethesda, MD) software by measuring at least 30 individual fibres randomly.

2.4b FTIR: The chemical structure of the nanofibrous membranes was examined by Fourier transform infrared spectroscopy (ATR-FTIR) unit (NICOLET IS5). The transmittance of each material $\mathrm{PU}, \mathrm{NaHCO}_{3}$, PA and $\mathrm{PU}-\mathrm{NaHCO}_{3}-$ PA composites were recorded over the range of 600-4000 $\mathrm{cm}^{-1}$ at 32 scans $\mathrm{min}^{-1}$ and averaged at the resolution of 4 $\mathrm{cm}^{-1}$. Zinc selenium (ZnSe) was used as ATR crystal and the FTIR outline of each sample was drawn, baseline corrected and normalized using the Spekwin32 software.

2.4c Porosity and pore size distribution: The porosity of the electrospun membranes was determined using apparent density method. A small sample from each membrane was cut into rectangular shape. Then, their weight and dimensions were measured. And the porosity was calculated using the 
following formula:

$$
\text { Porosity }=\frac{V \times \rho-m}{V} \times 100 \% \text {, }
$$

where $V$ is the volume of the sample, $m$ the measured weight and $\rho$ the specific gravity of PU (Tecoflex EG $80 \mathrm{~A}$ ), which is $1.04 \mathrm{~g} \mathrm{~cm}^{-3}$. The mean value was determined from the three samples. Further, the mean pore size and porosity distribution in both PU and $\mathrm{PU}-\mathrm{NaHCO}_{3}-\mathrm{PA}$ composites were measured using Image $\mathrm{J}$ and a graphical representation was also generated.

2.4d Contact angle assay: The wettability of the electrospun membranes was examined using contact angle measurement unit (VCA Optima, AST Products, Inc., USA). The membranes were cut into rectangular samples $(10 \mathrm{~mm} \times$ $10 \mathrm{~mm}$ ) and placed on the measuring stage. Subsequently, a water droplet of size $1 \mu \mathrm{l}$ was placed on the samples from a motorized syringe and the contact angle was measured immediately (within $10 \mathrm{~s}$ ). The mean value was determined from the three samples.

\subsection{Haemocompatibility studies}

All protocols related to the blood usage were approved by the independent ethical committee with the reference no. 201607211 at the Universiti Teknologi Malaysia. Blood $(12 \mathrm{ml})$ was procured by venipuncture from drug-free healthy adult human donors and anti-coagulated with tri-sodium citrate in the volumetric ratio of 9:1. The platelet-poor plasma (PPP) needed for APTT and PT assay was isolated from whole blood by centrifuging at $3000 \mathrm{rpm}$ for $10 \mathrm{~min}$ and the citrated whole blood was used for the haemolysis assay.

2.5a APTT: The time for blood coagulation through the intrinsic pathway was examined through activated partial thromboplastin time (APTT) assay. The membranes were cut into samples and placed in 96-well plates, where it was preincubated with PBS at $37^{\circ} \mathrm{C}$ for $30 \mathrm{~min}$.. Then, $50 \mu \mathrm{l}$ of PPP and rabbit brain cephalin was added and incubated at $37^{\circ} \mathrm{C}$ for 2 min. Finally, the reaction mixture was activated by adding $50 \mu \mathrm{l}$ of $\mathrm{CaCl}_{2}$ and gently stirred with a sterile steel needle until clot formation. The mean APTT was calculated from the three values.

2.5b PT: Prothrombin time (PT) was measured to assess the capacity of blood coagulation through the extrinsic pathway. The membranes placed in 96-well plates were preincubated with $\mathrm{PBS}\left(37^{\circ} \mathrm{C}, 30 \mathrm{~min}\right)$ and PPP was added subsequently. Then, $\mathrm{NaCl}$-thromboplastin reagent (Factor III) was added and the time taken for the clot formation was measured.

2.5c Haemolysis assay: Haemolysis ratio was determined to examine the percentage of red blood cell damage when the blood contacts the membrane. The test samples were equilibrated in physiological saline $(0.9 \mathrm{wt} / \mathrm{vol} \%)$ at $37^{\circ} \mathrm{C}$ for $30 \mathrm{~min}$ and incubated with aliquots of citrated blood diluted with saline $(4: 5)$ at $37^{\circ} \mathrm{C}$ for $60 \mathrm{~min}$ subsequently. The positive control was prepared by diluting aliquots of citrated blood with distilled water (4:5) and the physiological saline was used as negative control to avoid colouration. After incubation, the test samples and the positive control were centrifuged and the supernatant was collected to measure the absorbance of the samples at $542 \mathrm{~nm}$. Finally, the haemolysis ratio was calculated by using the following formula:

$$
\mathrm{HR}=\frac{\mathrm{TS}-\mathrm{NC}}{\mathrm{PC}-\mathrm{NC}} \times 100 \%,
$$

where TS is the absorbance value of test sample, NC is the absorbance of negative control and PC is the absorbance of positive control, respectively. The mean haemolysis ratio was determined from the three values.

\subsection{Statistical analysis}

Statistical analysis was performed through one-way analysis of variance (ANOVA). The difference between groups was compared with the level of significance of $P<0.05$.

\section{Results and discussion}

\subsection{SEM}

The topographical analysis revealed uniform, randomly interconnected, fibrous structure of the pristine PU scaffold (figure 1). However, after the addition of $\mathrm{PA}$ and $\mathrm{NaHCO}_{3}$, there was a significant change in the morphology. Among the three electrospun PU composites (with different ratios of $\mathrm{NaHCO}_{3}$ and PA), the PU-NaHCO $3-\mathrm{PA} 1$ and $\mathrm{PU}-\mathrm{NaHCO}_{3}$ -PA2 were expressed heavily beaded-discontinuous or broken fibrous structure. As shown in figure $2 \mathrm{a}$ and $\mathrm{b}$, even when the applied voltage and the flow rate were changed (table 2), the outcome remained the same (might be due to higher concentration of PA). But, the aforementioned drawbacks were not found in $\mathrm{PU}-\mathrm{NaHCO}_{3}-\mathrm{PA} 3$ and $\mathrm{PU}-\mathrm{NaHCO}_{3}-\mathrm{PA} 4$ membranes, which possess closely packed smooth nanofibres. In pristine PU, the average diameter of fibres was calculated as $349 \pm 47 \mathrm{~nm}$, while in $\mathrm{PU}-\mathrm{NaHCO}_{3}-\mathrm{PA} 3$ and $\mathrm{PU}-\mathrm{NaHCO}_{3}-\mathrm{PA} 4$ scaffolds, the mean diameter was reduced to $125 \pm 34$ and $175 \pm 43 \mathrm{~nm}$, respectively. This notable fall in the fibre diameter can be attributed to changes in physical properties of electrospinning solution, especially in the viscosity caused by the addition of PA and $\mathrm{NaHCO}_{3}$.

As mentioned in table 1 , the PU solution became less viscous followed by the blending of $\mathrm{NaHCO}_{3}$ and PA. This can be inferred from the slight increase in the mean diameter of fibres in $\mathrm{PU}-\mathrm{NaHCO}_{3}-\mathrm{PA} 4$ scaffold because, unlike $\mathrm{PU}-\mathrm{NaHCO}_{3}-\mathrm{PA} 3$, it contains only one part of composite 

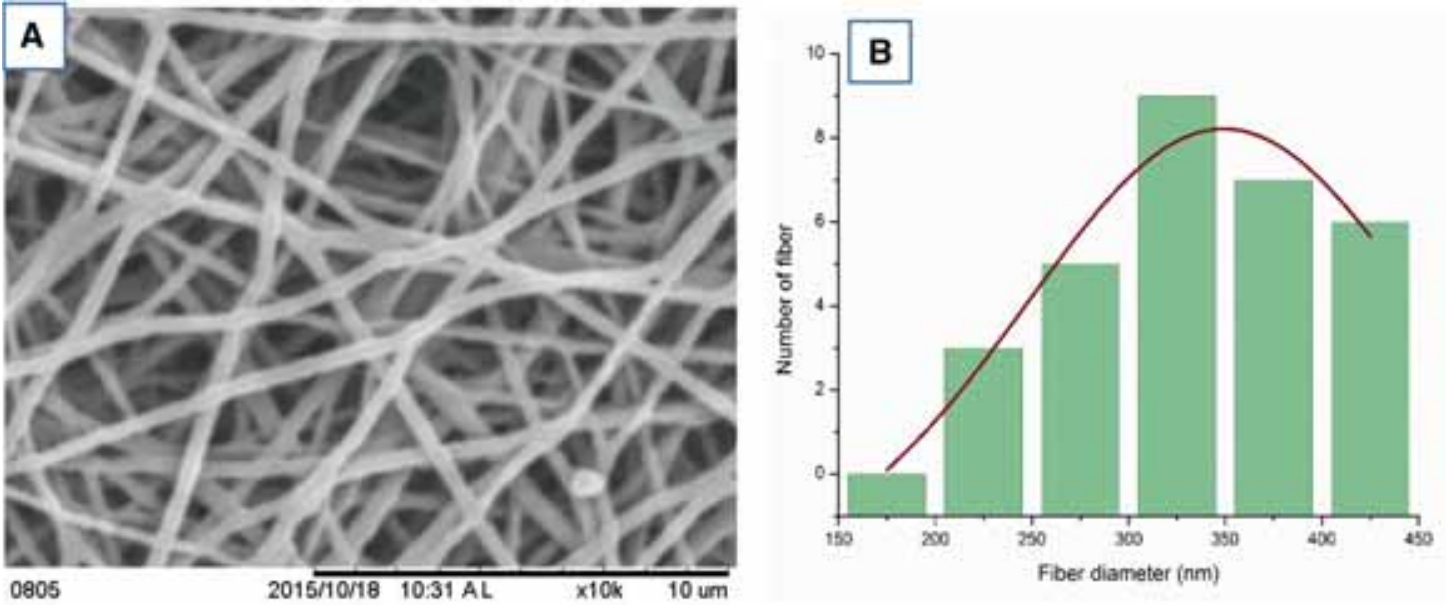

Figure 1. Representative SEM micrographs of pristine polyurethane (a) PU scaffold at magnification of $\times 10,000$ and (b) graph representing nanofiber diameter distribution.

mixture (table 1). Basically, when the viscosity of electrospun solution is low, the polymer jet experience greater bending instabilities which expands the fibre to a large extent before it reaches the collector. However, if the solution is extremely less viscous, it may form discontinuous broken fibres (as observed in $\left.\mathrm{PU}-\mathrm{NaHCO}_{3}-\mathrm{PA} 1\right)$ [18]. Zhao et al $[16,19]$ observed similar results, while blending $\mathrm{NaHCO}_{3}$ with PLLA and PLGA, respectively. In a different study, Fan et al [12] reported slight decrease in the diameter of electrospun silk fibres after adding PA and attributed it to the increase in electrical conductivity of the solution. Therefore, in addition to viscosity, a possible increase in conductivity of PU composite solution may also influence the fibre diameter and morphology. The role of properties such as diameter size, orientation and interconnec-tivity of fibres in promoting attachment and proliferation of various skin cells are well studied [5,20,21]. In addition, it also influences the blood compatibility and antimicrobial activity of the material by limiting the interaction with associated cell types [22,23]. Hence, the optimum features of the electrospun scaffold not only determine its ability to mimic native extracellular matrix (ECM), but also its biocompatibility. The smooth nanofibrous morphology of the synthesized composites is expected to be suitable for the rapid regeneration of skin cells supported by the gradual release of PA.

\subsection{Wettability}

Wettability is one of the vital parameters which play a decisive role in triggering the degradation of polymer bulk and also the release of payload [24]. Further, it also influences the ability of dressing material to absorb exudates, its regeneration and haemocompatible properties [25,26]. Hence, the contact angle assay was performed to characterize the wettability of the fabricated membranes. The test was performed in triplicates and the value represented is the mean of three different samples. As shown in figure 3, the pristine PU scaffold has a mean contact angle of $83.15 \pm 3.17^{\circ}$ and it is observed to be slightly hydrophobic. However, the water-loving substances in $\mathrm{PA}$ and $\mathrm{NaHCO}_{3}$ increased the spreading of a water droplet on the composite membranes. In $\mathrm{PU}-\mathrm{NaHCO}_{3}-\mathrm{PA} 3$ and $\mathrm{PU}-\mathrm{NaHCO}_{3}-\mathrm{PA} 4$, the mean contact angle was found to be $74.85 \pm 0.48^{\circ}$ and $80.17 \pm 1.96^{\circ}$, respectively. Though, the wettability of both composite membranes falls in the hydrophilic zone i.e., contact angle $<80^{\circ}$ [27], in statistical analysis, it was proven that only the $\mathrm{PU}-\mathrm{NaHCO}_{3}-\mathrm{PA} 4$ had a significant change in wettability compared to the pristine PU scaffold. This observed shift from slightly hydrophobic to hydrophilic can be attributed to the blending of $\mathrm{NaHCO}_{3}$ and PA. In most cases, the addition of natural, biological or chemical agents to a polymer has enhanced its hydrophilic properties [25,28,29]. In a study, Zhao et al [15] reported dose-dependant decrease in the contact angle of PLLA nanofibres after the blending of $\mathrm{NaHCO}_{3}$ and the contact angle was eventually dropped to zero at higher concentration. Even in this study, the reduction in the mixing ratio of composites with PU has influenceed the wettability.

\subsection{Surface chemistry}

The surface chemistry of pristine PU and the composite scaffolds was studied through FTIR analysis. The spectra of PU, $\mathrm{NaHCO}_{3}, \mathrm{PA}, \mathrm{PU}-\mathrm{NaHCO}_{3}-\mathrm{PA} 3$ and $\mathrm{PU}-\mathrm{NaHCO}_{3}-\mathrm{PA} 4$ are shown in figure 4 . The pristine and composite scaffolds exhibited several characteristic peaks of polyurethane. The $\mathrm{N}-\mathrm{H}$ stretching of an aliphatic primary amine group is represented by the peak at $3320 \mathrm{~cm}^{-1}$. Further, the peaks at 2940 , 2853 and $1410 \mathrm{~cm}^{-1}$ exhibit $\mathrm{C}-\mathrm{H}$ stretching and bending of alkanes. The twin peaks at 1726 and $1698 \mathrm{~cm}^{-1}$ indicated the $\mathrm{C}=\mathrm{O}$ stretching of carboxylic groups. Whilst the sharp peaks formed at 1220,1110 and $1072 \mathrm{~cm}^{-1}$ specify the 

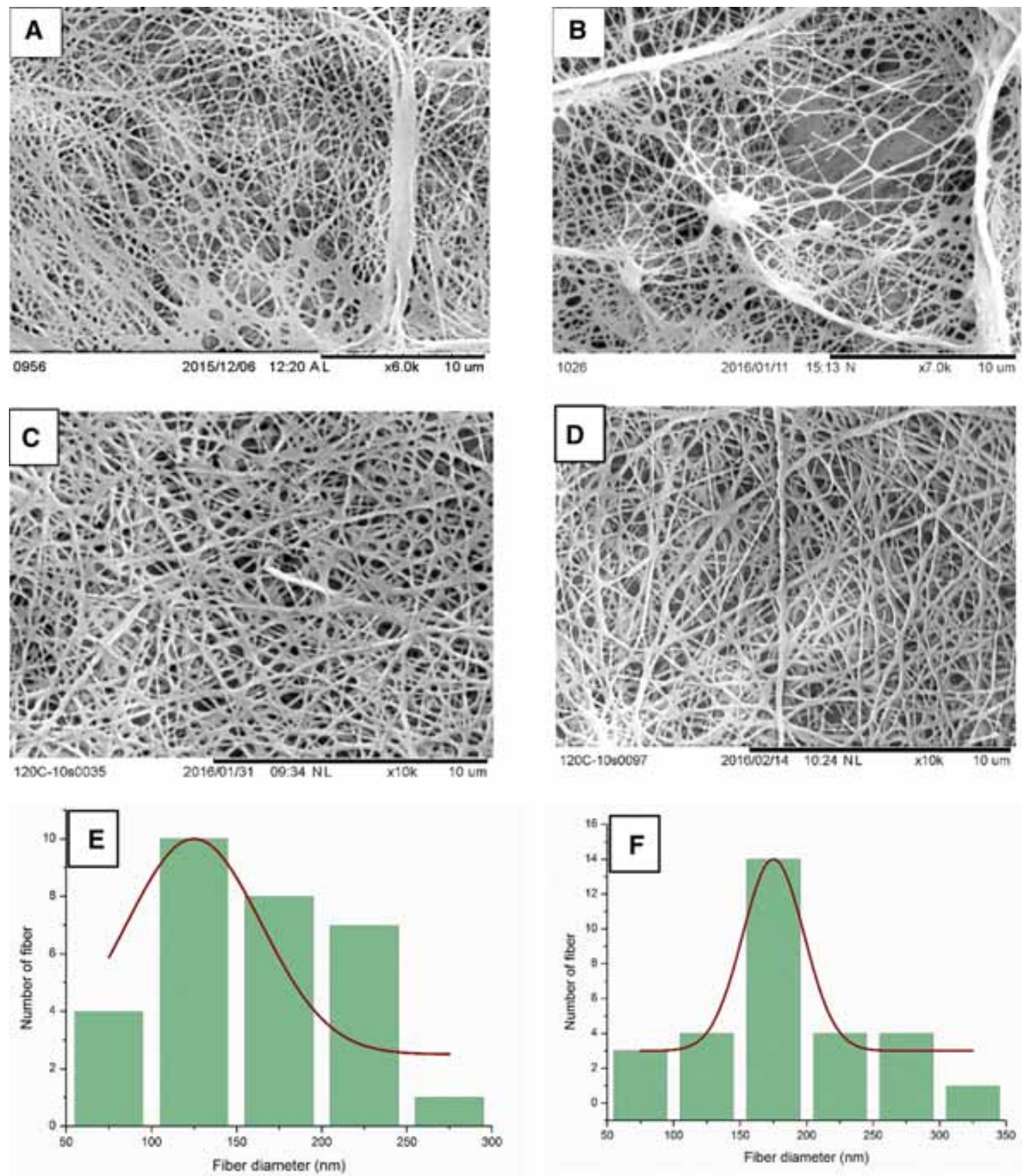

Figure 2. SEM image of the composite scaffolds (a) $\mathrm{PU}-\mathrm{NaHCO}_{3}-\mathrm{PA} 1$, (b) $\mathrm{PU}-\mathrm{NaHCO}_{3}-\mathrm{PA} 2$, (c) $\mathrm{PU}-\mathrm{NaHCO}_{3}-$ $\mathrm{PA} 3$, (d) PU-NaHCO $3-\mathrm{PA} 4$, (e and $\mathbf{f})$ graph representing nanofibre diameter distribution in the scaffolds.

$\mathrm{C}-\mathrm{O}$ stretching. The successful blending of $\mathrm{NaHCO}_{3}$ and PA can be inferred from the peak shifts and intensity changes in the FTIR spectra of the composites when compared to pristine PU. At the wavenumbers of 1570 and $1625 \mathrm{~cm}^{-1}$, the peak intensity strengthens for composites, which express the vibrational absorption of carboxyl and indicate the presence of $\mathrm{NaHCO}_{3}$. Zhao et al $[15,16]$ in his studies has observed similar absorption peaks due to the successful blending of $\mathrm{NaHCO}_{3}$ in acid-responsive PLLA [15] and PLGA nanofibrous composites [16].
Moreover, the increase in the intensity of PU characteristic peak at $3320 \mathrm{~cm}^{-1}$ depicts the addition of $\mathrm{NaHCO}_{3}$ and PA-specific hydrophilic groups. In general, the addition of biomolecules affects the intensity of certain $\mathrm{OH}$ specific peaks in FTIR spectrum (like $3200-3400 \mathrm{~cm}^{-1}$ ). If the substance contains water-loving groups, the intensity of $\mathrm{OH}$ specific peaks in the FTIR spectra of the composite may increase when compared with pristine one [30]. A similar result is obtained in this study and notably the intensity increase in the order of $\mathrm{PU}<\mathrm{PU}-\mathrm{NaHCO}_{3}-\mathrm{PA} 4<\mathrm{PU}-\mathrm{NaHCO}_{3}-\mathrm{PA} 3$ 


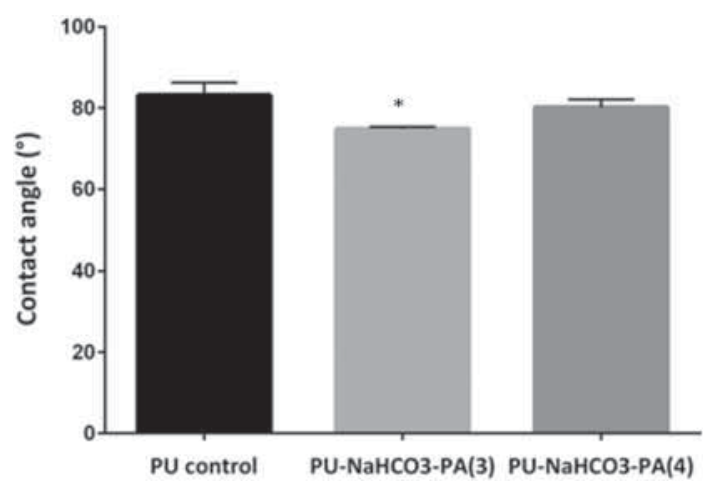

Figure 3. Contact angle of PU and the composite scaffolds. Value expressed in mean $\pm \mathrm{SD}$ and $*$ indicates statistical significance $(P<0.05)$.

(as shown in figure 4b), which corroborate and validate the results of contact angle assay. Hence, the optimum wettability and surface chemistry of the composite scaffold may play a significant role in delaying immune system activation and speed-up the regeneration of wound surface.

\subsection{Porosity and pore size distribution}

Interconnected porous morphology is one of the special features in electrospun scaffolds, which is essential for the cell migration, infiltration of nutrients and gas exchange. In addition, the pore size also influences the cell recruitment since the optimum pore size changes between cell types. Thus, the dressing material developed to treat chronic wounds should possess optimum porosity to support the regeneration of skill cells such as fibroblasts, keratinocytes, etc. As shown in figure 5, the pristine PU had a percentage porosity of $65.7 \pm 3.8 \%$, while in $\mathrm{PU}-\mathrm{NaHCO}_{3}-\mathrm{PA} 3$ and PU- $\mathrm{NaHCO}_{3}-\mathrm{PA} 4$, porosity was calculated as $79.4 \pm 4.8$ and $71.4 \pm 5.7 \%$, respectively. When compared with PU, the composites have expressed better porosity, which might be due to its comparatively dense fibrous morphology. Notably, in $\mathrm{PU}-\mathrm{NaHCO}_{3}-\mathrm{PA} 3$, the difference was significant with nearly $20 \%$ increase. Basically, the scaffolds with a porosity of $>70 \%$ are reported to be ideal for supporting the regeneration of skin cells [31-33]. In addition, the pores in the pristine PU were largely distributed between 10 and $70 \mu \mathrm{m}$, whereas in the composite scaffolds, it was reduced to 20-50 $\mu \mathrm{m}$.

The composite scaffolds, especially the $\mathrm{PU}-\mathrm{NaHCO}_{3}-$ PA3 is observed to have superior physicochemical and structural properties like wettability, surface chemistry and porosity. However, an ideal dressing material used for chronic wounds should also possess good blood compatible properties to minimize the intervention of natural healing mechanism by the immune system.

\subsection{Coagulation assays-APTT and PT}

The dressing material used to treat chronic wounds needs to control the typical host response triggered by non-native substances like thrombosis (contact activated), inflammation and foreign body reaction. Otherwise, the undesired host reaction may further delay the healing process [34]. Hence, the haemocompatibility of the fabricated scaffolds was studied by performing APTT, PT and haemolysis assays. The pristine PU was noted to have an APTT and PT time of $72.93 \pm 19.4$ and $25.73 \pm 2.84$ s, respectively. As expected, the composites had delayed the clotting of blood through both intrinsic and extrinsic pathways. Among the two composites, the PU- $\mathrm{NaHCO}_{3}-\mathrm{PA} 3$ expressed significant results with APTT time of $109.97 \pm 11.31 \mathrm{~s}$ and PT of $29.56 \pm 2.37 \mathrm{~s}$, as shown in figures 6 and 7. The observed improvement in the haemocompatibility of composites can be attributed to the reported changes in wettability and surface chemistry caused by the blending of $\mathrm{NaHCO}_{3}$ and PA. This effect is also reported by Wang et al [35]. They determined that a higher wettability (due to the addition of keratin and AgNP) prolonged the APTT and thus, improves the blood compatibility of PU mats. Similarly, in another research group, Quiang et al [36] observed that the addition of acrylic acid significantly delayed the APTT time from $46.8 \pm 3 \mathrm{~s}$ in pristine PU to $>150 \mathrm{~s}$ in PU-acrylic acid blend. However, the PT of PU and the acrylic acid composites have not expressed much difference. When compared to APTT, the blood coagulation time through extrinsic pathway has always resulted in lesser improvement [35-37]. But, in all the above cases, the coagulation time was enhanced in proportion to the mixing percentage of biomolecules or other chemical substances. Hence, the decline in APTT and PT time of PU- $\mathrm{NaHCO}_{3}-\mathrm{PA} 4$ when compared to $\mathrm{PU}-\mathrm{NaHCO}_{3}-\mathrm{PA} 3$ can be attributed to its limited changes in the wettability and surface chemistry.

\subsection{Haemolysis assay}

Haemolysis ratio depicts the percentage of red blood cell damage when the blood comes in contact with the membrane and it has to be as low as possible. The results shown in figure 8 reveals that there is no significant difference in haemolysis ratio between the pristine PU and the composite membranes. The PU control had a haemolysis ratio of $3.64 \pm 0.83 \%$, while in $\mathrm{PU}-\mathrm{NaHCO}_{3}-\mathrm{PA} 3$ and $\mathrm{PU}-\mathrm{NaHCO}_{3}-\mathrm{PA} 4$, the ratio was $3.52 \pm 1.25$ and $3.21 \pm 1.36 \%$, respectively. Developed composites' haemolysis ratio is almost similar to the pure PU control, but relatively lower value because of the change in the wettability as reported previously due to the successful blending of $\mathrm{NaHCO}_{3}$ and PA.

Based on the above results, both PU and composites can be categorized as slightly haemolytic substances, since the haemolytic index is between 5 and 2\% [38]. Therefore, from the results of various physicochemical and haemocompatibility tests, it can be realized that the fabricated advanced 

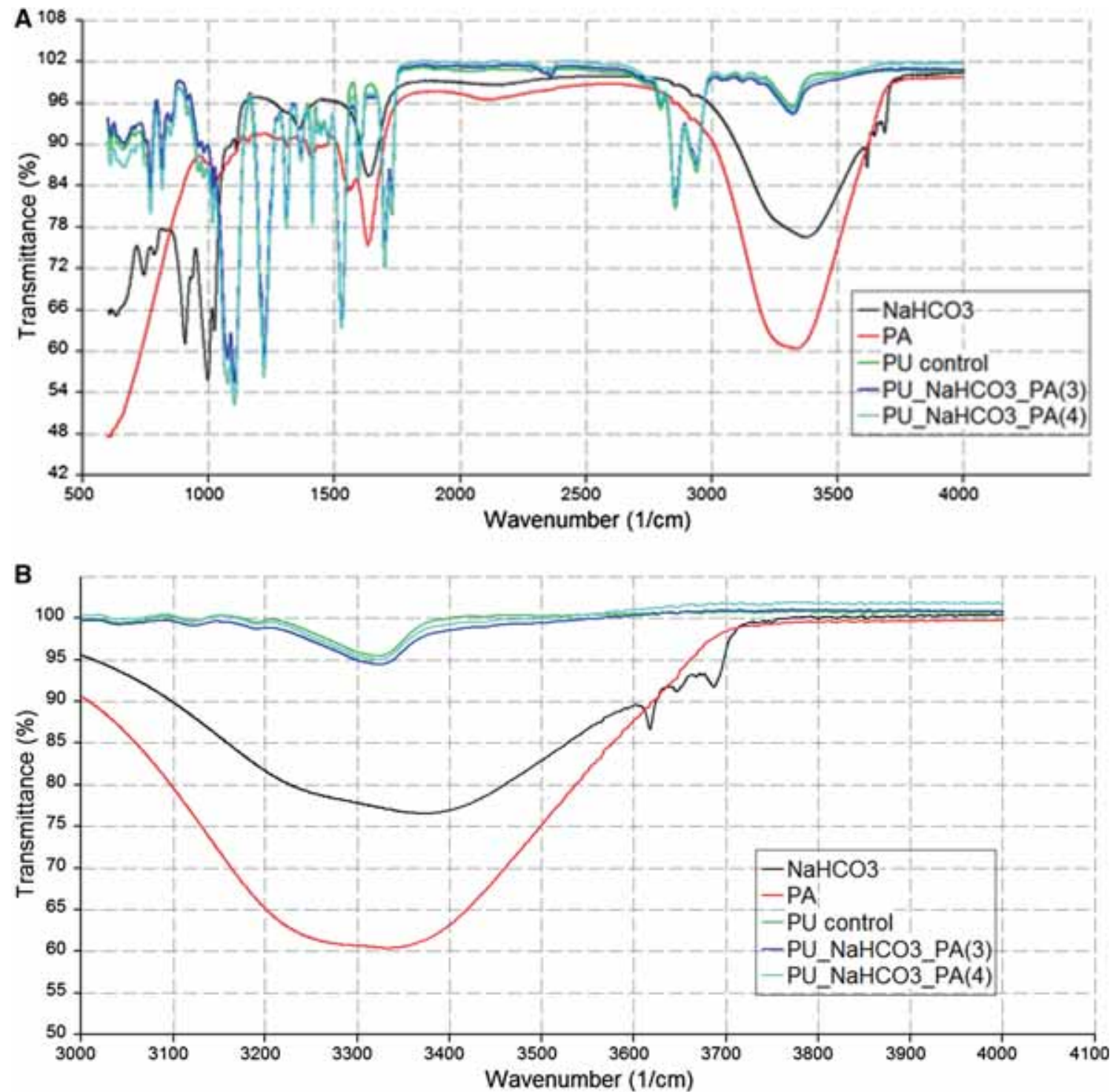

Figure 4. Recorded Fourier transform infrared (FTIR) spectrum of pristine PU and composite membranes.

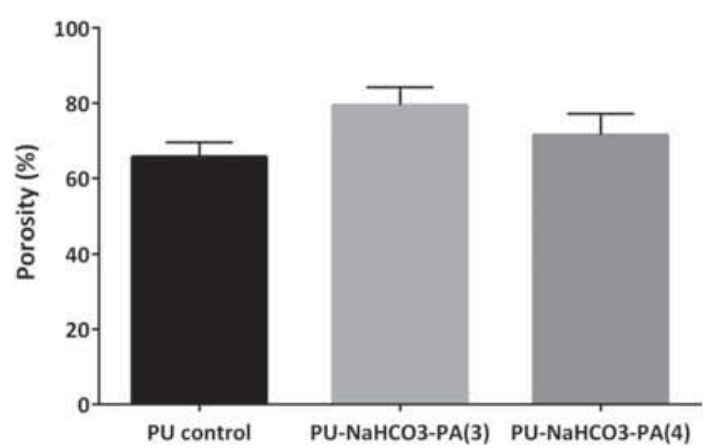

Figure 5. Porosity measurement of the $\mathrm{PU}, \mathrm{PU}-\mathrm{NaHCO}_{3}-\mathrm{PA} 3$ and $\mathrm{PU}-\mathrm{NaHCO}_{3}-\mathrm{PA} 4$ scaffolds. Value expressed in mean $\pm \mathrm{SD}$ and $*$ indicates statistical significance $(P<0.05)$.

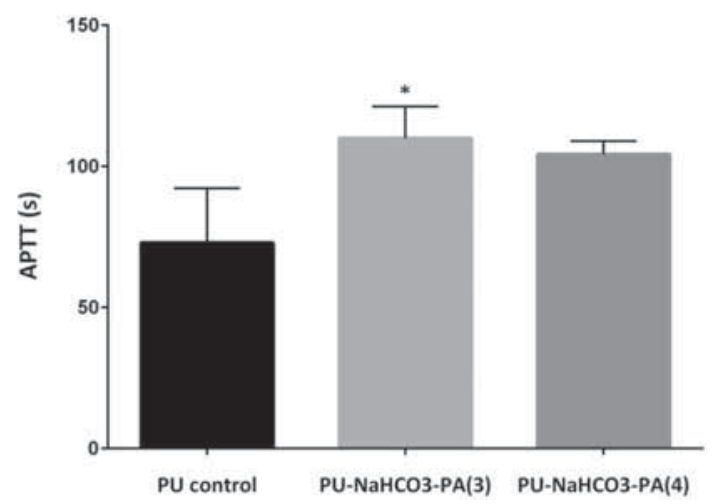

Figure 6. Activated partial thromboplastin time of the PU control, $\mathrm{PU}-\mathrm{NaHCO}_{3}-\mathrm{PA} 3$ and $\mathrm{PU}-\mathrm{NaHCO}_{3}-\mathrm{PA} 4$. Value expressed in mean $\pm \mathrm{SD}$ and $*$ indicates statistical significance $(P<0.05)$. 


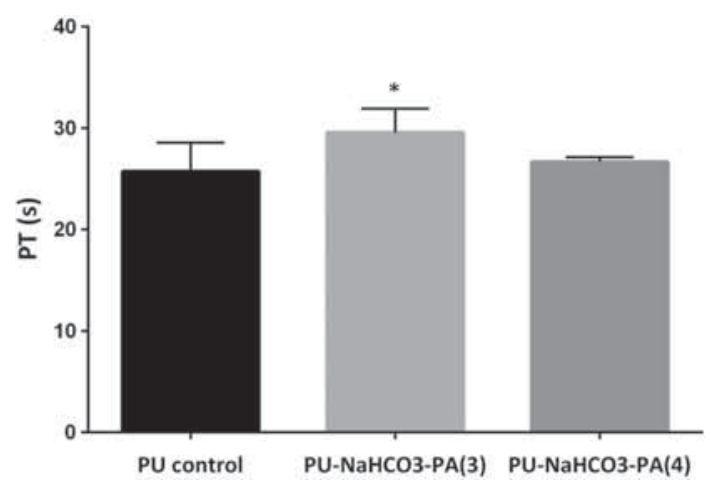

Figure 7. Prothrombin time of the pristine $\mathrm{PU}$, $\mathrm{PU}-\mathrm{NaHCO}_{3}-\mathrm{PA} 3$ and $\mathrm{PU}-\mathrm{NaHCO}_{3}-\mathrm{PA} 4$. Value expressed in mean $\pm \mathrm{SD}$ and $*$ indicates statistical significance $(P<0.05)$.

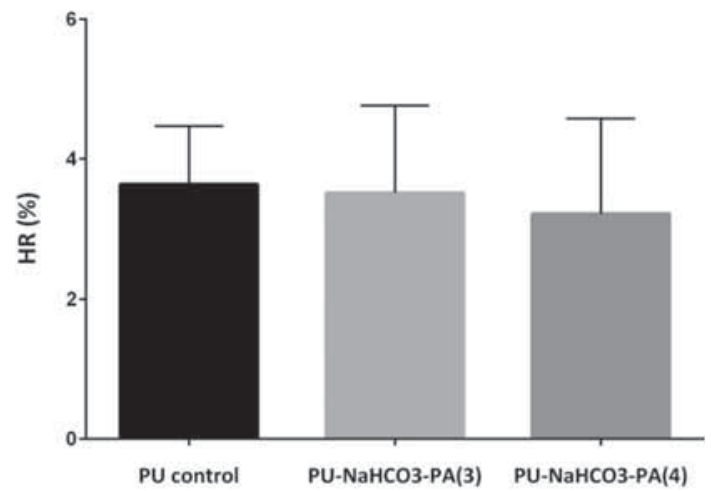

Figure 8. Haemolysis ratio of the pristine $\mathrm{PU}$ and the composite membranes $\mathrm{PU}-\mathrm{NaHCO}_{3}-\mathrm{PA} 3$ and $\mathrm{PU}-\mathrm{NaHCO}_{3}-\mathrm{PA} 4$.

nanofibrous textile has the potential to provide a viable platform for the timely healing of chronic wounds.

\section{Conclusion}

In this study, different types of $\mathrm{PU}-\mathrm{NaHCO}_{3}-\mathrm{PA}$ composite scaffolds were successfully fabricated and subjected to various characterization tests. When compared to pristine PU, the composites scaffold demonstrated better wettability, changes in surface chemistry, smooth fibrous morphology with interconnected pores and haemocompatible properties. Of the two different composites, the $\mathrm{PU}-\mathrm{NaHCO}_{3}-\mathrm{PA} 3$ displayed significant changes, thus, it may be effective in absorbing exudates, allowing the inflow of nutrients and recruiting the skin cells. Moreover, the $\mathrm{pH}$ assisted the release of PA may control typically delayed inflammation process, and also increase in the accumulation and proliferation of fibroblasts at the wound site. Though the fabricated advanced textile possesses promising physicochemical and blood compatible properties, its cytocompatibility and antimicrobial effects are need to be studied to realize its potential. This is vital to understand how the included components may react with skin cells and microbes at the wound site.

\section{Acknowledgements}

This work was partially supported by a research university Grant, Vot Numbers Q.J130000.2545.12H80 and Q.J130000. 2545.14H59.

\section{References}

[1] Kennedy J F and Bunko K The use of 'smart' textiles for wound care. (United Kingdom: Advanced Science and Technology Institute)

[2] Petrulyte S 2008 Dan. Med. Bull. 5572

[3] Parham S, Chandren S, Wicaksono H B, Bagherbaigi S, Lee S L, Yuana L S et al 2016 RSC Adv. 68188

[4] Tong S F, Yip J, Yick K and Yuen C M 2015 Text Res. J. 85 1258

[5] Abrigo M, McArthur S L and Kingshott P 2014 Electrospun. Macromol. Biosci. 161

[6] Frykberg R G and Banks J 2015 Adv. Wound Care 4560

[7] Richmond N A, Maderal A D and Vivas A C 2013 Dermatol. Ther. 26187

[8] Optimal Care of Chronic, Non-Healing 2013 Lower extremity wounds: a review of clinical evidence and guidelines (Ottawa, Canada: Canadian Agency for Drugs and Technologies in Health)

[9] Rieger K A, Birch N P and Schiffman J D 2013 J. Mater. Chem. 14531

[10] Gunatillake P A and Raju A 2003 Eur. Cell. Mater. 51

[11] Reza G, Hamid Y, Lactoee R, Hassan A and Zuhair M 2015 ACS Appl. Mater. Interf. 724296

[12] Fana L, Caib Z, Zhanga K, Han F, Li J, Hea J et al 2014 Colloids Surf. B 11714

[13] Nicolaidou E and Katsambas A D 2000 Clin. Dermatol. 1887

[14] Draelos Z D 2000 Curr. Probl. Dermatol. 35235

[15] Zhao J, Liu S, Li B, Yang H, Fan C and Cui W 2013 Macromol. Biosci. 13885

[16] Zhao J and Cui W 2014 Nanosci. Nanotech. Lett. 6339

[17] Thirumal M, Khastgir D, Singha N K, Manjunath B S and Naik Y P 2008 J. Appl. Polym. Sci. 1081810

[18] Balaji A, Vellayappan M V, John A A, Subramanian A P, Jaganathan S K, Supriyanto E et al 2015 RSC Adv. 557984

[19] Yuan Z, Zhao J, Zhu W, Yang Z, Li B, Yang H et al 2014 Biomater. Sci. 2502

[20] Pelipenko J, Kocbek P and Kristl J 2015 Eur. J. Pharm. Sci. 66 29

[21] Hsia H C, Nair M R, Mintz R C and Corbett S A 2011 Plast. Reconstr. Surg. 1272312

[22] Liu R, Qin Y, Wang H, Zhao Y, Hu Z and Wang S 2013 BMC Cardiovasc. Disord. 1379

[23] Abrigo M, Kingshott P and McArthur S L 2015 ACS Appl. Mater. Interf. 77644

[24] Hu C and Cui W 2012 Adv. Healthcare Mater. 186

[25] Kim S E, Heo D N and Lee J B 2009 Biomed. Mater. 4 044106 
[26] Menzies K L and Jones L 2010 Optom. Vis. Sci. 87387

[27] Hoda J, Saeid K, Majid H E, Masoud S, Zeina K and Zahra Z 2011 Cell J. 1431

[28] Rajan U A, Gopalsamy G, Yesupatham S, Soo L Y and Sang K C 2014 Carbohydr. Polym. 102884

[29] Rajan U A, Arathyram S, Kurup R, Priya M, Malarvizhi G, Dongmei W et al 2015 Int. J. Biol. Macromol. 771

[30] Balaji A, Jaganathan S K, Ismail A F and Rajasekar R 2016 Int. J. Nanomed. 114339

[31] Yang M H, Max S R, Xin J, Brianna J R, Wendy C C, Fang P X et al 2013 Mater. Sci. Eng. C 334767

[32] Meng Z X, Wang Y S, Ma C, Zheng W, Li L and Zheng Y F 2010 Mater. Sci. Eng. C 301204
[33] Vaz C M, van Tuijl S, Bouten C V C and Baaijens F P T 2005 Acta Biomater. 5575

[34] Balaji A, Jaganathan S K and Vellayappan M V 2015 RSC Adv. 569660

[35] Wang Y, Li P, Xiang P, Lu J, Yuan J and Shen J 2016 J. Mater. Chem. B 4635

[36] Quiang L V, Chuanbao C and Hesun Z 2004 J. Mater. Sci. Mater. Med. 15607

[37] Tanzi M C, Resnati M, Lampugnani M G, Anouchinsky R, Ambrosio L, Mambrito B et al 1993 Clin. Mater. 12 17

[38] Fazley M, Elahi G G and Lu W 2014 Rev. Adv. Mater. Sci. 75 38148 